\title{
Title
}

\section{Poverty in behavioral research: Different operationalizations, different results}

\section{Author list}

Matúš Adamkovič ${ }^{1,2,3}$, Marcel Martončik ${ }^{1}$, Martin Lačný ${ }^{4}$, and Monika Kačmárová ${ }^{1}$

${ }^{1}$ Institute of psychology, Faculty of Arts, University of Presov, Slovakia

${ }^{2}$ Institute of social sciences, CSPS Slovak Academy of Sciences, Slovakia

${ }^{3}$ Center for meta-research in education, Faculty of Education, Charles University, Czechia

${ }^{4}$ Institute of political science, Faculty of Arts, University of Presov, Slovakia

Corresponding author: matho.adamkovic@gmail.com

\section{Review Accessibility}

The full review on poverty measures in top cited studies from social and behavioral sciences is available at https://rpubs.com/Matho/poverty measures.

\section{Data Accessibility}

Data, R code, and analytic outputs are freely available at https://osf.io/v4yrf/.

\section{Funding}

This work was funded by the Slovak Research and Development Agency [project no. APVV-150404] and project PRIMUS/20/HUM/009.

\begin{abstract}
Poverty is a complex phenomenon involving objective as well as subjective aspects. In reality, 9 out of 10 flagship studies from social sciences assess only objective indicators reducing poverty's multidimensional nature into solely economic characteristics. Comparing the effects of several distinct poverty operationalizations on the same outcome variable, we found substantial heterogeneity in the estimates. Neglecting the fact that different poverty operationalizations produce different results can generate misleading narratives when interpreting the findings. A researcher should be well-aware which poverty operationalization is the most suitable for their research purposes prior to the data collection. In case this is hard to determine, we aim to encourage researchers to perform sensitivity analyses based on different poverty operationalizations in order to inspect how these choices shape their outcomes.
\end{abstract}

Key words: poverty; objective poverty; subjective poverty; poverty measurement 


\section{Introduction}

Throughout our lives, we all have developed a notion of what poverty is and how to define it. This intuitive common-sense conceptualization of poverty (e.g., poverty is when a person does not have enough money to make ends meet) might appear to be consensual, at least from laypeople's perspective. But when a researcher aims to study poverty's correlates from, say, psychological viewpoint, they hit the wall very early as there exists no agreement amongst scholars on how to exactly define poverty, or, from a slightly different perspective, who can be considered poor. This situation would not be so surprising considering the lack of good theory (see, e.g., Gigerenzer, 2010; Muthukrishna \& Henrich, 2019) and the 'toothbrush problem' (Mischel, 2008) in social and behavioral sciences, but given the more economical nature of poverty, one would legitimately expect such an important concept to have a stronger theoretical foundation. It is even fair to question the validity of the different poverty thresholds as proposed by policymakers - are the criteria upon which a poverty line is set theoretically justifiable with respect to its intended purpose? And what purpose it, in fact, is? The probability of solving such an extensive issue in a single paper converges to zero, however, we believe it is important to explicitly emphasize on a crucial point - the variability of the construct of poverty. Since an ideal operationalization of poverty does not (and probably could not) exist, we argue that the concept of so-called researcher degrees of freedom (Simmons, Nelson, \& Simonsohn, 2011; Wicherts, Veldkamp, Augusteijn, Bakker, van Aert, \& van Assen, 2016) applies not only to technical aspects of designing a study or analyzing data, but should be taken into account as early as defining the constructs. In this paper, we first provide a summary of a systematic review focused on poverty measurement practices. Afterwards, we will demonstrate the extent to which different poverty operationalizations shape the results when studying the effect of poverty on psychological variables.

\section{Different poverty operationalizations}

The multidimensional nature of poverty (economic, demographic, social, cultural, and political attributes; see Costa \& De Angelis, 2008) makes it more difficult to reach a consensus on which areas of life should be included when measuring poverty. In general, there are three main types of poverty operationalization: objective, subjective, and multidimensional. Objective poverty is defined by factors that are not dependent on personal opinion and perceptions of individuals. It is based on an analysis of available socio-economic information on households or household files. This approach defining poverty on the basis of financial resources (income, wealth, consumption level, etc.) is conventional and widely used in the methodologies of the World Bank (Ravallion, 2010). Income poverty measures are taken from the utilitarian understanding of wealth, with an emphasis on individual utility as the key variable. It has, however, been recognized that neither income nor consumption (even with seemingly appropriate normalizations) can be considered as sufficient statistics for measuring welfare (Ravallion, 2012) and that relative poverty measures are needed (Ravallion \& Chen, 2019). The weaknesses in the objective approach are mainly 
related to the suitability and interpretation of utility as a measure of welfare. There is also the problematic interpersonal comparability of utility for which there is no suitable empirical procedure in addition to strict cardinal utility functions (Klasen, 2000). As the result of the ongoing criticism, scholars argue that the nature of economic welfare goes beyond objective indicators like GDP and instead, researchers should switch the emphasis to subjective indicators of economic situation/well-being (see Aitken, 2019).

In contrast to objective approaches, the subjective concept of poverty is based on the belief that an individual is best placed to assess the urgency of their needs and to hierarchize the order of their satisfaction (e.g., by evaluating their life situation as un/favorable) in a given social reference framework. Respondents are asked to self-assess their economic welfare (Shams, 2015), or broader concepts, such as satisfaction with life or happiness. Alternatively, the respondent provides money metrics of points on qualitative welfare scales, for instance, the minimum income needed to make ends meet (Minimum Income Question; see e.g., Clark, Frijters, \& Shields, 2008). Intrinsically, the subjective poverty operationalizations are based on Sen's $(1992,1999)$ capability approach to poverty. The capability approach defines the poor as persons who have limited freedom or chances to realize their own lifestyles. Financial resources are only one of the means in achieving certain well-being in this sense and defining poverty, therefore, focuses directly on 'well-being outcomes'. Poverty is then defined as the inability of people to achieve a minimum level of so-called vital capabilities (e.g., inability to be healthy, well dressed, have decent housing, etc.). On one hand, this viewpoint overcomes the multiple issues in defining poverty through approaches based solely on financial resources - for example, heterogeneity in human behavior, the influence of public goods on individual well-being, as well as methodological pitfalls associated with the utilitarian calculus of utility. On the other hand, it is problematic to select the relevant skills and set the trade-offs (relative weights) across the dimensions. There is also relatively limited availability of reliable data on non-monetary variables suitable for international comparison.

Multidimensional poverty measures (e.g., Human Development Index, Global Multidimensional Poverty Index) might seemingly serve as a solution to the issues related to both objective and subjective approaches. Nevertheless, as Ravallion (2012) states, recognizing that welfare is 'multidimensional' and that income is an incomplete metric, does not mean we can credibly collapse the distinct dimensions of poverty (e.g., education, health, living standards) into a single, unidimensional, space. Unless the research question requires the researcher to employ a specific set of items, a safe practice in assessing economic well-being might be to use a combination of income, consumption and welfare (Annoni \& Weziak-Bialowolska, 2016). The assessment of non-objective poverty indicators is, naturally, accompanied by heterogeneity in responses. Those variations could stem from idiosyncratic 'mood' effects, personality traits or simply errors.

\section{Poverty, it's dichotomization, and range restriction}


Behavioral scientists and especially economists often incline toward the notion of poverty as a binary variable - people are either poor or not. This classification is usually based on a certain cut-off representing a poverty line (Pantazis, Gordon, \& Levitas, 2006). Unlike a natural dichotomization (e.g., biological sex), such an artificial dissection of a phenomena should be very well justifiable. We agree that under specific conditions, for example, when policy makers have to clearly identify a target group that will receive some form of support (e.g., free meal programs for children) the dichotomization might be relevant. However, for most of research and data analysis, such dichotomization is likely more harmful than beneficial as it inherently leads to loss of information and is likely to lead to loss of statistical power, lowered effect sizes or to problems when synthesizing the studies in a meta-analysis (for a more in-depth criticism of this practice see, for example, Altman \& Royston, 2006; Cohen, 1983; MacCallum, Zhang, Preacher, \& Rucker, 2002; Maxwell \& Delaney, 1993; Royston, Altman, \& Sauerbrei, 2005). In some cases, poverty dichotomization determines the process of sample selection when researchers recruit only people they define as poor. For example, according to a widely used poverty line, only people with gross income per month lower than $60 \%$ of the population median will be sampled. Poverty is, therefore, often defined as an extreme part of the whole spectrum of economic indicators, which is inherently leading to a lower variability of the observed data. A situation when the research sample is more homogeneous (the standard deviation is smaller in the selected sample than in the entire population) than a population from which the sample is drawn, is known as range restriction (Pedhazur \& Pedhazur Schmelkin, 1991; Sireci \& Sukin, 2013). Range restriction may occur in any correlational research (Sackett, Lievens, Berry, \& Landers, 2007). In the restricted samples, the correlation coefficients are usually (notably) lower than they would have been in the case of sampling participants from an entire spectrum of a population (see, e.g., Bland \& Altman, 2011). The problem with dichotomization/range restriction in poverty research can be demonstrated in the flagship research by Mani, Mullainathan, Shafir, and Zhao (2013), published in Science, in which the authors conducted a set of laboratory experiments showing that poverty impedes cognitive functions. In their analyses, the authors dichotomized poverty on median income. Reanalyzing their data using the whole spectrum of income, Wicherts and Scholten (2013) failed to corroborate their findings. Instead, they highlight "spurious interactions between income and experimental manipulation due to ceiling effects caused by short and easy tests. This suggests that effects of financial worries are not limited to the poor" (Wicherts \& Scholten, 2013, p. 1169).

\section{A review of poverty measurement practices}

To examine how frequent certain poverty operationalizations/measures are, we carried out a systematic review on the most-cited papers from social and behavioral sciences published in the last decade. We screened 500 most-cited studies (based on data from WoS Core Collection) from which we selected papers dealing with primary empirical research and extracted basic information related to the poverty measurement. Specifically, we coded whether (1) poverty was measured or a priori expected in the sample; (2) poverty was dichotomized or not; and (3) range 
restriction based on poverty status occurred or not. When poverty was measured, we inspected whether the measure was objective, subjective, or multidimensional. Considering the diversity in the objective measures, we furthermore clustered those that we deemed similar and created a comprehensible classification system.

The whole workflow as well as more detailed results accompanied with data and code are available as stand-alone materials at: https://rpubs.com/Matho/poverty_measures.

In summary, out of 228 studies, about one third used some sort of poverty transformation with a binary outcome (this excludes studies that used a poverty threshold to calculate a continuous variable of interest; e.g., income-to-needs ratio), while about $6 \%$ directly restricted sampling procedure to involve only people in poverty. Notably, at least one objective poverty measure was used in more than $93 \%$ of the studies, whereas less than $5 \%$ of the studies employed a subjective or a multidimensional poverty measure, respectively. The gap between the frequency of usage of objective measures $(N=272)$ in comparison to subjective $(N=12)$ and multidimensional $(N=$ 10) measures is striking. In other words, 9 out of 10 poverty measures in the most-cited papers from social and behavioral sciences (excluding economics) are of objective nature. Despite the numerous calls for the inclusion of subjective/multidimensional perspective into research practices, the data show they are heavily underrepresented in the leading literature. Naturally, neglecting this crucial piece of information can generate misleading narratives when interpreting the results.

\section{Different operationalizations, different results}

As we mentioned earlier, despite the enormous prevalence of objective measures, they are far from being the only option of poverty operationalization. But do subjective measures eventually provide researchers with different information than objective measures? Do they really lead to different conclusions? In the following part of this paper, we will demonstrate the extent to which different poverty operationalizations shape the results when studying the effect of poverty on psychological variables. The aim of this analysis is not to capture poverty in its full complexity, but rather to show that a researcher should be well-aware which operationalization of poverty is the most suitable one for their research purposes prior to the data collection. In the case this is not possible, we aim to encourage researchers to perform sensitivity analyses based on different poverty operationalizations in order to inspect how these choices determine their outcomes.

\section{Method}

Participants

For the purposes of other research, we had collected 2 datasets $\left(N_{1}=430 ; N_{2}=500\right)$. Both consisted of adult Slovak inhabitants $\left(M_{\text {agel }}=40.05, S D_{\text {agel }}=11.48 ; M_{\text {age } 2}=39.57, S D_{\text {age } 2}=\right.$ 
11.47), most of them employed and having a high school degree. The women to men ratio was almost 1:1 in both datasets. Median equivalized net household income was 533 and $565 €$ per month, with $S D$ s of 295 and $328 €$ (note: at the time of data collection, the median personal net income was about 675 and $720 €$, respectively; these data were derived from the official gross income statistics provided by the Statistical Office of the Slovak Republic; 2019). In order to gather data from all self-governing regions of Slovakia, the data were collected online via an agency specialized in data collection and marketing research. After completing the test battery,

participants were compensated by a small reward in the form of points which they can use to buy various products offered by the agency. The datasets were cleansed for careless responders and screened for improbable values. The resulting datasets consist of 419 and 485 participants, respectively.

\section{Measures}

Given the available data, we decided to use 2 common measures that researchers interested in psychological correlates of poverty could decide to study - subjective satisfaction with life and perceived stress. We measured these constructs by the Satisfaction with life scale (SWLS; Diener, Emmons, Larsen, \& Griffin, 1985) and the Perceived stress scale (Cohen, Kamarck, \& Mermelstein, 1983). We observed high reliabilities of both measures in both datasets, with the omega total coefficients ranging from .84 to .88 .

Since we aimed to inspect how different operationalizations of poverty can lead to different results, we extracted several possible poverty measures/operationalizations from our data. Specifically, we have worked with: $a$ ) equivalized household net income (Hagenaars, De Vos, \& Zaidi, 1994); b) household net income; c) personal net income; $d$ ) categorized personal income; $e$ ) objective SES (occupational status, level of education, and income); $f$ ) subjective perception of economic situation (a 5-point scale created by the authors consisting of 6 items like, for example, "how satisfied are you with your current economic situation?". $\omega_{\text {total }}=.92-.93$;) $\mathrm{g}$ ) subjective SES (Giatti et al., 2012); $h$ ) subjective SMS (Giatti et al., 2012); $i$ ) subjective assessment of own poverty/wealth; $j$ ) subjective assessment of household's poverty/wealth (available only in the second dataset); $k$ ) make ends meet question (Nygård, Härtull, Wentjärvi, \& Jungerstam, 2017; available only in the second dataset); l) 60\% of median household income threshold (poverty as a binary variable; e.g., Eurostat, 2018); $m$ ) $40 \%$ of median household income threshold (poverty as a binary variable; e.g., Pantazis et al. 2006); n) 60\% of median personal income threshold (poverty as a binary variable; e.g., Eurostat, 2018); o) 40\% of median personal income threshold (poverty as a binary variable; e.g., Pantazis et al. 2006); $p$ ) personal net income after restricting the sample to participants below $60 \%$ median income threshold; $q$ ) subjective perception of economic situation (see the point $f$ ) after restricting the sample to participants below $60 \%$ median income threshold.

Data analysis 
In order to examine heterogeneity of the results, we conducted two multilevel multivariate metaanalyses, one synthesizing the effects of different poverty operationalizations on SWLS and the other one on perceived stress. Conducting a multilevel meta-analysis allows to examine heterogeneity of the observed effects between clusters (i.e., to what extent does the observed effects differ across studies) and also within-cluster (i.e., to what extent does the effects vary within one study). $I^{2}$ statistic was used to assess the relative heterogeneity of the observed effects (Borenstein, Higgins, Hedges, \& Rothstein, 2017). The percentage of within-cluster heterogeneity will, in this case, indicate how different poverty operationalizations affect the outcome variable. In other words, high within-cluster heterogeneity will imply that the differences in the effect sizes should be attributed to the different poverty operationalization. On the other hand, low heterogeneity in general or high between-clusters heterogeneity will suggest that distinct poverty operationalization does not play an important role in regard to the obtained results. To visually demonstrate the results, forest plots were created.

Prior to computing the meta-analytic models, the effect sizes were extracted by either correlating (Spearman's Rho) the specific poverty operationalization with SWLS/perceived stress or by running t-tests (this apply to the 4 situations in which poverty was considered as a binary variable). In the case of the latter, Cohen's $d$ s were calculated based on the t-tests results, then converted to Pearson's $r$ adjusting for the sample size in each group, and then again converted to Spearman's Rho. All the analyses were conducted in R (R Core Team, 2019) using psych (Revelle, 2019) and metafor (Viechtbauer, 2010) packages.

\section{Results}

As depicted in the forest plot (Figure 1), point estimates of the obtained effect sizes ranged from .03 to .54 (within the same dataset) for satisfaction with life and from -.09 to -.31 (within the same dataset) for perceived stress. Speaking in relative values, even if we omit the extreme difference between poverty operationalizations observed in the case of satisfaction with life $(\Delta \rho$ in Study $1=.51$ ), the magnitudes of the largest correlations are about 2-4 times bigger compared to the smallest one. Even intuitively, these variations in effect sizes appear to be substantial, especially for the satisfaction with life meta-analytic model. Relative heterogeneity estimates indeed revealed that heterogeneity is caused by differences in poverty operationalizations, whereas the results replicated fairly well between the datasets. In the life satisfaction model, the heterogeneity was very high $\left(I^{2}=92.25\right.$ or 93.03 using Jackson's approach) and all of it could be attributed to the within-cluster variation of the effect sizes. The situation was less extreme in the second meta-analytic model. In the case of perceived stress, a small-to-medium heterogeneity $\left(I^{2}\right.$ $=28.26$, or $40.97 \%$ using Jackson's approach) was observed, all of it attributed to the heterogeneity within-cluster. The observed heterogeneity estimates indicate that variation in the effect sizes was dependent on the specific poverty measurement and could be a serious issue when neglected. 
Figure 1: Forest plots for satisfaction with life and perceived stress meta-analytic models

Meta-analytic model for satisfaction with life

Poverty operationalization

Correlation $[95 \% \mathrm{Cl}]$

\section{Study 1}

Equivalized household income

Household income

Personal income

Personal income - categories

Objective SES

Subjective economic situation

Subjective SES

Subjective poverty/wealth

Household income below $60 \%$ median

Household income below $40 \%$ median

Personal income below $60 \%$ median

Personal income - restricted

Subjective economic situation - restricted

Study 2

Equivalized household income

Household income

Personal income

Personal income - categories

Objective SES

Subjective economic situation

Subjective SES

Subjective poverty/wealth

Subjective poverty/wealth household

Make ends meet

Household income below $60 \%$ median

Household income below $40 \%$ median

Personal income below $60 \%$ median

Personal income below $40 \%$ median

Personal income - restricted

Subjective economic situation - restricted

RE model for both studies

both studies

\begin{tabular}{cccccc|}
\hline & 1 & 1 & & & \\
-0.2 & 0.0 & 0.2 & 0.4 & 0.5 & 0.7 \\
& & Observed outcome (Spearmans's Rho) & &
\end{tabular}
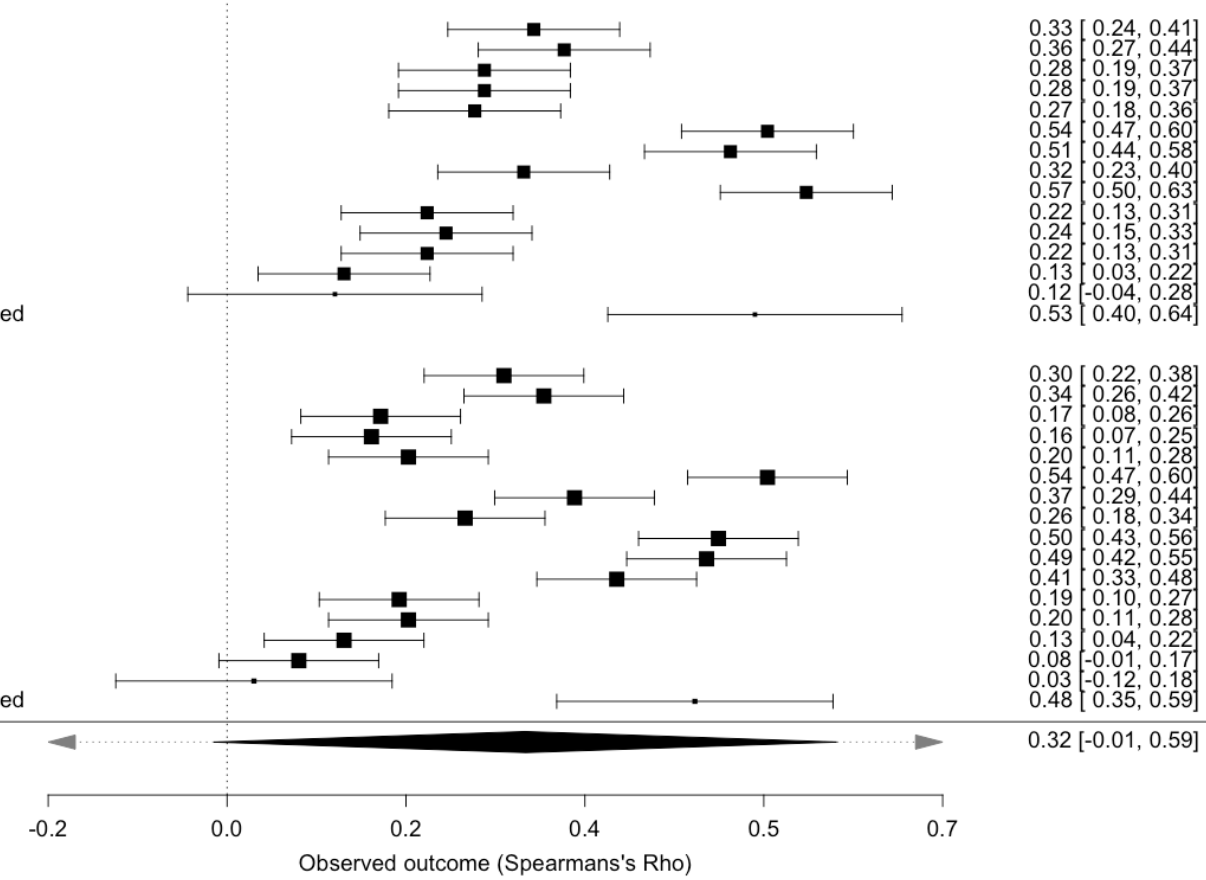

Poverty operationalization

Meta-analytic model for stress

\section{Study 1}

Equivalized household income

Household income

Personal income

Personal income - categories

Objective SES

Subjective economic situation

Subjective SES

Subjective SMS

Subjective poverty/wealth

Household income below $60 \%$ median

Pousenold income below

Personal income below $40 \%$ median

Personal income - restricted

Subjective economic situation - restricted

Study 2

Equivalized household income

Household income

Personal income

Personal income - categories

Objective SES

Subjective economic situation

Subjective SES

Subjective SMS

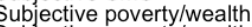

Subjective poverty/wealth household

Household income below $60 \%$ median

Personal income below $60 \%$ median

Personal income below $40 \%$ median

Personal income - restricted

Subjective economic situation - restricted

RE model for both studies
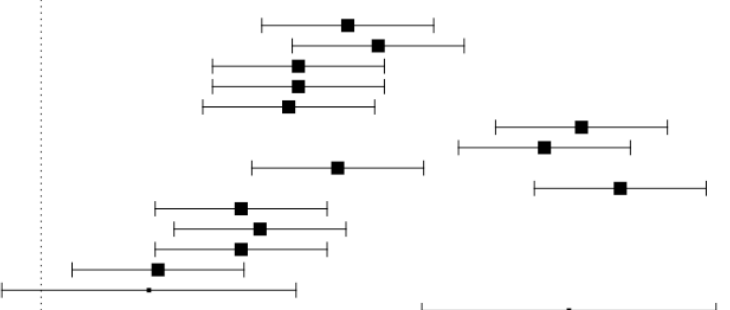

$0.53[0.40,0.64]$

lic model for stress
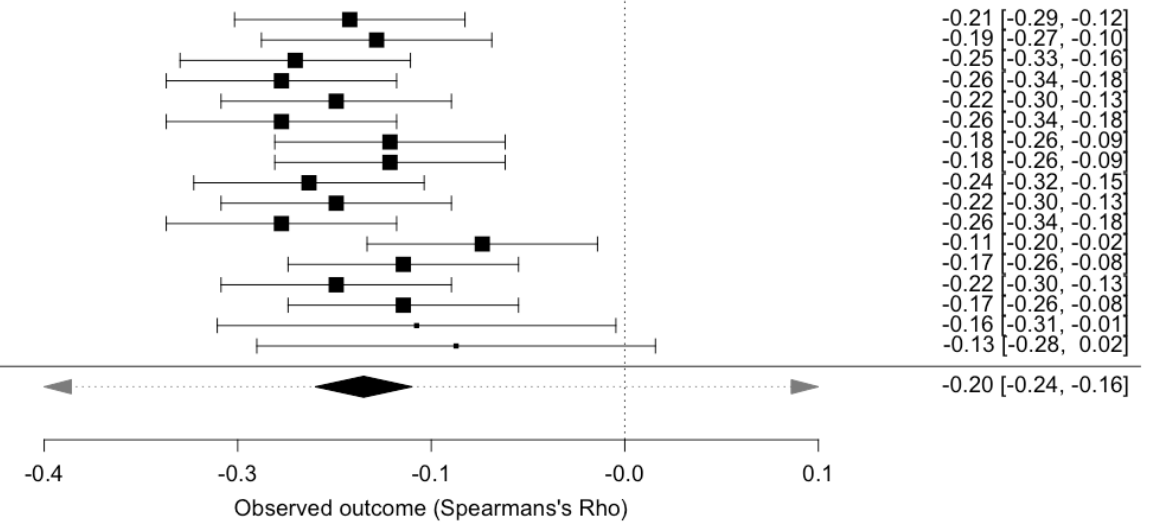


\section{Discussion}

Our review showed a huge overreliance of the leading poverty-related literature on objective measures. If the prevalence of other than objective measures is far below $10 \%$, putting it simply, we are probably disregarding a very important piece of evidence that could have a substantial impact on our findings. The above-presented variations in estimates suggest a major practical implication - the conclusion of a research indeed depends on the specific way poverty is operationalized. Although the different operationalizations are complementary, their mutual substitution might be problematic. The presented findings might legitimately raise several questions. Are the scores obtained from measures which assess one's economic situation valid? If so, in which situations? Is it meaningful to dichotomize economic status? Do we, in fact, have appropriate tools to measure poverty or is it a complex system which we lack a formal theory to describe and adequately capture?

Validity of a score directly depends on the problem the researcher aims to solve. For an illustration, if the researcher tries to explain the mechanism of delayed gratification, administering a subjective assessment of SES, say, on a visual scale should be both reliable and valid. Given the research question, employing a subjective measure of economic situation is probably even more appropriate than addressing objective economic indicators. In other words, one's present-future trade-off related to poverty might be shaped by subjective, psychological (Haushofer \& Fehr, 2014; Sheehy-Skeffington \& Haushofer, 2014) or sociological factors (see, e.g., Jachimowicz, Chafik, Munrat, Prabhu, \& Weber, 2017; Jachimowicz, Szaszi, Lukas, Smerdon, Prabhu, \& Weber, 2020) rather than by the objective situation. This, however, does not mean that the measurement of objective economic situation is inherently redundant, it just brings in a different piece of information, which could, too, be valuable. On the other hand, if the researcher is interested in examining, say, the extent to which economic situation predicts health outcomes, usage of objective economic indicators might appear to be more valid. After the researcher decides whether to employ economic, psychological or multidimensional poverty operationalization, it might remain unclear which specific measure should be used. In the majority of situations, it might be difficult to distinguish whether one measure of objective situation is better than another (e.g., whether equivalized household income is more informative and accurate than personal income given a specific research question or vice versa) and researchers usually arbitrarily or intuitively opt only for one of those. In such cases, we highly recommend using several measures and to properly report them in a sensitivity analysis.

Under some specific circumstances, poverty dichotomization could be a justified (although perhaps still not optimal) choice. For example, if a policymaker aims to study the effect of a financial intervention on low-income households, which can then have practical implications, they might set some threshold and study only people who fall below a certain level of income. As we discussed above, such choices usually lead to observation of lower effect sizes or to an often neglected phenomenon called Simpson's paradox (i.e., in a subgroup of a population, the 
direction of an association can be reversed in comparison to the whole population that comprises the subgroup; Kievit, Frankenhuis, Waldorp, \& Borsboom, 2013). Our results confirm that range restriction indeed attenuated the observed effect size (e.g., from .17 to .03 or from -.26 to -.13 ). Apart from practical consequences in the interpretation of such results, this fact emphasizes on even more important cautionary note from a philosophical perspective. Dichotomizing poverty is tricky because of the related problems concerning its ambiguity, vagueness and a large number of its plausible definitions. As discussed by MacCallum et al. (2002), dichotomization of a variable should be performed when there exist distinct groups of individuals on the variable and the dichotomized measure more appropriately represents those groups. Inferences then should be made taking into account group differences rather than individual differences. As demonstrated by the sorites paradox (also known as the paradox of the heap), such identification of distinct groups based on income is hardly possible. If someone is poor and will be given one euro, they will not escape the poverty circle. But if one euro will be given to the person for long enough, after some time, they will be (and probably will also feel) less poor and after some more time, they will not be poor at all. However, we cannot draw an exact line when the transformation from being poor to being non-poor suddenly happened. Similarly, if, say, $460 €$ is considered a cut off value, does it mean that a person with $461 €$ is no longer poor? Does this person differ significantly in some attributes from those with income equal or lower than $460 €$ ? Will this $1 €$ make the group really distinct? From the philosophical point of view, it is impossible to find an exact, non-arbitrary, cut-off that could meaningfully separate such groups and make them distinct (Chakravarty, 2018; Qizilbash, 2006). Categorizing people to those above and below poverty level is a product of artificial dichotomization based on one or many quantitative variables. Therefore, dichotomizations based on poverty lines of the median are very inaccurate simplifications (Chakravarty, 2018). Considering poverty's fuzzy conceptualization, an individual has a certain propensity to poverty in the whole spectrum of income (Ciani, Gagliardi, Riccarelli, \& Betti, 2018) and, therefore, poverty should be conceptualized as a continuous variable representing "the degree of membership to the poverty set" (Neff, 2013, p. 322).

It is crucial to realize that, regardless of how sophisticated the poverty assessment is, most of the operationalizations and related measures will produce some bias. We thus argue that, in many cases, improving the research question (i.e., having it well-justified in terms - what phenomenon do I aim to study? Which population do I care about in this study? What will my outcome be and how does it relate to the sampled population? What implications I expect?) should precede and, in fact, be superior to choosing the appropriate measure/measures. Clarifying the research question and apprehending the theory upon which the research question/prediction was built could greatly facilitate the decision-making process of choosing the most suitable poverty operationalization. Taking this all into account, we conclude by several practical recommendations on how to improve poverty measurement: (1) Have a well-justified research question; (2) Choose your measure (be it objective, subjective, or multidimensional) accordingly; (3) If no measure is preferred, employ several types of measures and conduct a sensitivity analysis - report all the measures transparently (pre-registering the study will help); (4) Do not 
dichotomize people to those above and those below a certain threshold, unless you have a solid rationale to do so; (5) If you, for some reason, specifically aim to conduct your research on a sample of people living in poverty, be aware of range restriction and possible Simpson's paradox that are likely to impact both the effect size you observe and the generalizability of your findings.

\section{Limitations and future directions}

We identified a few limits of the study. A major concern could be related to the selection of the analyzed variables. The dependent variables, stress and satisfaction with life, were chosen purposefully, as they are often present in the social science research dealing with poverty. At the same time, these variables were present in both of our datasets. Thus, we believe that inclusion of these two variables, in fact, increases the robustness and credibility of our results. The same also applies to the selection of different poverty operationalizations. As the reported systematic review was carried out after the data had been collected (some non-systematic literature searches were done before the data were collected), the operationalizations in the present analysis do not represent the exact findings from the review. Nonetheless, at the time of data collection, the research team was fully aware of different possibilities of poverty measurement, and thus, the here-employed measures represent a relevant sample of poverty measurement possibilities, including several subjective measures that are underrepresented in the literature. Unfortunately, as no multidimensional measures were incorporated in the data collections, we were not able to infer about their effects on the outcome variables.

The traditional approaches to poverty (be it objective, subjective, or even multidimensional) seem to be, in fact, missing a core characteristic of the construct - its complexity. A fundamental feature of any poverty measure is that it creates a "score" or an index, simplifying the phenomenon into one number. This is not necessarily a fault of the existing measures but rather of the way we perceive poverty from the conceptual viewpoint. If poverty is indeed a complex phenomenon of a multidimensional nature which mixes objective and subjective indicators, then a switch of perspective might be needed. Nowadays, we can witness an evolution in the field of psychopathology as an increasing number of researchers aims beyond the traditional conceptualizations of the mental disorders (i.e., a disorder is a latent factor causing the observable indicators) towards better-representing network models. The emerging field of network psychometrics (see, e.g., Borsboom \& Cramer, 2013) has already found its way into other subfields of psychology (e.g., social, personality) and could surely serve as a great inspiration for poverty research. This novel approach allows researchers to study poverty as a complex dynamic system of mutually related variables. Estimating a network model of poverty could provide unique valuable insights into its structure. For instance, it could show which variables play a more important role (e.g., are more central; have the strongest connections with the other variables; have the most connections with the other variables) and which ones are more peripheral. This can, in turn, help to define what poverty is by creating a more realistic profile of 
this phenomenon. Knowing which specific aspects of poverty to target when making interventions will consequently increase the chances for a successful poverty alleviation.

\section{Conclusion}

In practice, poverty research in social sciences heavily relies on objective indicators, with as few as 1 out of 10 studies involving other than objective type of measure. Alternative assessment of economic situation provides a researcher with a different sort of information. This, in turn, should be reflected in a variation in the observed estimates when comparing their effects on the same variable. Indeed, as demonstrated by our analysis, different poverty operationalizations yielded different results given the same outcome variable. Being aware of the researcher degrees of freedom is one of the first steps in obtaining more accurate information about the world. Taking into account the empirical evidence, we would like to highlight the importance of using several operationalizations of a construct, especially in the case the most suitable one simply does not exist. Reporting this sort of sensitivity analysis will help to understand how the effect changes when no strong uniform theory underlying the construct is provided. The existence of many distinct poverty definitions (Bibi, 2005; Clark, 2018; Kingdon \& Knight, 2006; Ravallion, 1994) underlines how complex, however vague, this phenomenon is. Performing sensitivity analysis using several theoretically justifiable operationalizations is, therefore, more than welcome. Although we are aware of some essential caveats of such approach (e.g., selectively reporting only the operationalizations that have brought the desired result; see point D3 by Wicherts et al., 2016), we believe that these days, the research community has learned from the replication crisis and definition-hacking (which slightly differs from the outcome reporting bias) will not become another questionable research practice. Instead, this flexibility will be used to critically evaluate the results brought by different operationalizations and consequently increase ecological validity of the research. Applying this practice to the research on poverty, a researcher could compare monetary, psychological or multidimensional approaches and interpret these results accordingly, allowing for a better insight into generalizability or applicability of their findings.

\section{Funding}

This work was funded by the Slovak Research and Development Agency [project no. APVV-150404] and project PRIMUS/20/HUM/009.

\section{Conflict of interest}

None.

\section{Acknowledgement}


The data used in this study were collected as a part of a bigger data collection for the research grant APVV-15-0404 "Psychological causes and consequences of poverty".

\section{Review Accessibility}

The full review on poverty measures in top cited studies from social and behavioral sciences is available at https://rpubs.com/Matho/poverty_measures.

\section{Data Accessibility}

Data, R code, and analytic outputs are freely available at https://osf.io/v4yrf/.

\section{Authors' Contributions}

MA, MM, and ML conceived the main idea, theoretical framework, and design of the study. MK, MM, and MA carried out the review. MA performed the statistical analyses. All authors have revised the manuscript, made a substantial contribution to this work, and approved it for publication.

\section{References}

Aitken, A. (2019). Measuring Welfare Beyond GDP. National Institute Economic Review, 249, R3-R16. doi:10.1177/002795011924900110

Altman, D. G., \& Royston, P. (2006). The cost of dichotomising continuous variables. BMJ, 332(7549), 1080.1. doi:10.1136/bmj.332.7549.1080

Annoni, P., \& Weziak-Bialowolska, D. (2016). A Measure to Target Antipoverty Policies in the European Union Regions. Applied Research in Quality of Life, 11(1), 181-207. doi:10.1007/s11482-014-9361-z

Bibi, S. (2005). Measuring Poverty in a Multidimensional Perspective: A Review of Literature (November 1, 2005). PEP Working Paper No. 2005-07. doi: 10.2139/ssrn.850487

Bland, J. M., \& Altman, D. G. (2011). Correlation in restricted ranges of data. BMJ, 342, d556d556. doi:10.1136/bmj.d556

Borenstein, M., Higgins, J. P. T., Hedges, L. V., \& Rothstein, H. R. (2017). Basics of metaanalysis: $\mathrm{I}^{2}$ is not an absolute measure of heterogeneity. Research Synthesis Methods, 8(1), 5-18. doi:10.1002/jrsm.1230

Borsboom, D., \& Cramer, A. O. J. (2013). Network Analysis: An Integrative Approach to the Structure of Psychopathology. Annual Review of Clinical Psychology, 9(1), 91-121. doi:10.1146/annurev-clinpsy-050212-185608

Chakravarty, S. R. (2018). Fuzzy Set Approaches to the Measurement of Multidimensional Poverty. Analyzing Multidimensional Well-Being, 163-199.

doi:10.1002/9781119257424.ch4 
Ciani, M., Gagliardi, F., Riccarelli, S., \& Betti, G. (2018). Fuzzy Measures of Multidimensional Poverty in the Mediterranean Area: A Focus on Financial Dimension. Sustainability, 11(1), 143. doi:10.3390/su11010143

Clark, A., Frijters, P., \& Shields, M. (2008). Relative Income, Happiness and Utility: An Explanation for the Easterlin Paradox and Other Puzzles. Journal of Economic Literature, 46(1), 95-144. doi: 10.1257/jel.46.1.95

Clark, A. (2018). Four Decades of the Economics of Happiness: Where Next? Review of Income and Wealth, 64(2), 245-269. doi:10.1111/roiw.12369

Cohen, J. (1983). The Cost of Dichotomization. Applied Psychological Measurement, 7(3), 249253. doi:10.1177/014662168300700301

Cohen, S., Kamarck, T., \& Mermelstein, R. (1983). A Global Measure of Perceived Stress. Journal of Health and Social Behavior, 24(4), 385. doi:10.2307/2136404

Costa, M, \& De Angelis, M. (2008). The multidimensional measurement of poverty: A fuzzy set approach. Statistica, 68(3), 303-319. doi:10.6092/issn.1973-2201/3536

Diener, E., Emmons, R. A., Larsen, R. J., \& Griffin, S. (1985). The Satisfaction With Life Scale. Journal of Personality Assessment, 49(1), 71-75. doi:10.1207/s15327752jpa4901_13

Eurostat. (2018). Glossary: At-risk-of-poverty rate. Retrieved from: https://ec.europa.eu/eurostat/statistics-explained/index.php?title=Glossary:At-risk-ofpoverty threshold

Gigerenzer, G. (2010). Personal Reflections on Theory and Psychology. Theory \& Psychology, 20(6), 733-743. doi:10.1177/0959354310378184

Hagenaars, A. J. M., De Vos, K., \& Zaidi, A. (1994). Poverty statistics in the late 1980s: Research based on micro-data. Luxembourg: Office for official publications of the European Union.

Haushofer, J., \& Fehr, E. (2014). On the psychology of poverty. Science, 344(6186), 862867. doi:10.1126/science. 1232491

Jachimowicz, J. M., Chafik, S., Munrat, S., Prabhu, J. C., \& Weber, E. U. (2017). Community trust reduces myopic decisions of low-income individuals. Proceedings of the National Academy of Sciences, 114(21), 5401-5406. doi:10.1073/pnas.1617395114

Jachimowicz, J. M., Szaszi, B., Lukas, M., Smerdon, D., Prabhu, J., \& Weber, E. U. (2020). Higher economic inequality intensifies the financial hardship of people living in poverty by fraying the community buffer. Nature Human Behaviour. doi:10.1038/s41562-0200849-2

Kievit, R. A., Frankenhuis, W. E.,, Waldorp, L., \& Borsboom, D. (2013). Simpson's Paradox in Psychological Science: A Practical Guide. Frontiers in psychology, 4:513. doi:10.3389/fpsyg.2013.00513

Kingdon, G., \& Knight, J. (2006). Subjective well-being poverty vs. Income poverty and capabilities poverty? The Journal of Development Studies, 42(7), 1199-1224. doi:10.1080/00220380600884167

Klasen, S. (2000). Measuring Poverty and Deprivation in South Africa. Review of Income and Wealth, 46(1), 33-58. doi:10.1111/j.1475-4991.2000.tb00390.x 
MacCallum, R. C., Zhang, S., Preacher, K. J., \& Rucker, D. D. (2002). On the practice of dichotomization of quantitative variables. Psychological Methods, 7(1), 19-40. doi:10.1037/1082-989x.7.1.19

Mani, A., Mullainathan, S., Shafir, E., \& Zhao, J. (2013). Poverty Impedes Cognitive Function. Science, 341(6149), 976-980. doi:10.1126/science.1238041

Maxwell, S. E., \& Delaney, H. D. (1993). Bivariate median splits and spurious statistical significance. Psychological Bulletin, 113(1), 181-190. doi:10.1037/0033-2909.113.1.181

Mischel, W. (2008). The toothbrush problem. Association for Psychological Science Observer, $21,11$.

Muthukrishna, M., \& Henrich, J. (2019). A problem in theory. Nature Human Behaviour, 3 (3), 221-229. doi:10.1038/s41562-018-0522-1

Neff, D. (2013). Fuzzy set theoretic applications in poverty research. Policy and Society, 32(4), 319-331. doi:10.1016/j.polsoc.2013.10.004

Nygård, M., Härtull, C., Wentjärvi, A., \& Jungerstam, S. (2017). Poverty and old age in Scandinavia: a problem of gendered injustice? Evidence from the GERDA survey in Finland and Sweden. Social Indicators Research, 132, 681-698.

Pantazis, C., Gordon, D., \& Levitas, R. (2006). Poverty and social exclusion in Britain. Bristol, The Policy Press.

Pedhazur, E. J., \& Pedhazur Schmelkin, L. (1991). Measurement, design, and analysis. An integrated approach. New Jersey: Lawrence Erlbaum Associates, Inc.

Qizilbash, M. (2006). Philosophical Accounts of Vagueness, Fuzzy Poverty Measures and Multidimensionality. Economic Studies in Inequality, Social Exclusion and Well-Being, 9-28. doi:10.1007/978-0-387-34251-1_2

R Core Team. (2019). R: A language and environment for statistical computing. R Foundation for Statistical Computing, Vienna, Austria. Retrieved from http://www.R-project.org

Ravallion, M. (1994). Poverty Comparisons. Chur: Harwood Academic Press.

Ravallion, M. (2010). Poverty Lines across the World. Policy Research Working Paper 5284. World Bank: Development Research Group.

Ravallion, M. (2012). Poor, or Just Feeling Poor? On Using Subjective Data in Measuring Poverty. Policy Research Working Paper 5968. World Bank: Development Research Group.

Ravallion, M., \& Chen, S. (2019). Global poverty measurement when relative income matters. Journal of Public Economics, 177, 104046. doi:10.1016/j.jpubeco.2019.07.005

Revelle, W. (2019). psych: Procedures for Psychological, Psychometric, and Personality Research. Northwestern University, Evanston, Illinois. https://CRAN.Rproject.org/package $=$ psych

Royston, P., Altman, D. G., \& Sauerbrei, W. (2005). Dichotomizing continuous predictors in multiple regression: a bad idea. Statistics in Medicine, 25(1), 127-141.

doi:10.1002/sim.2331 
Sackett, P. R., Lievens, F., Berry, C. M., \& Landers, R. N. (2007). A cautionary note on the effects of range restriction on predictor intercorrelations. Journal of Applied Psychology, 92(2), 538-544. doi:10.1037/0021-9010.92.2.538

Sen, A. (1992). Inequality Reexamined. Cambridge: Harvard University Press.

Sen, A. (1999). Development as Freedom. New York: Knopf.

Sheehy-Skeffington, J., Haushofer, J. (2014). The behavioural economics of poverty. In United Nations Development Programme Istanbul International Center for Private Sector in Development (Ed.), Barriers to and opportunities for poverty reduction: Prospects for private sector-led interventions.

Shams, K. (2015). Developments in the Measurement of Subjective Well-Being and Poverty: An Economic Perspective. Journal of Happiness Studies, 17(6), 2213-2236. doi:10.1007/s10902-015-9691-z

Simmons, J. P., Nelson, L. D., \& Simonsohn, U. (2011). False-Positive Psychology. Psychological Science, 22 (11), 1359-1366. doi:10.1177/0956797611417632

Sireci, S. G., \& Sukin, T. (2013). Test validity. In K. F. Geisinger (Ed.), APA Handbook of testing and assessment in psychology: Vol. 1. Test theory and testing and assessment in industrial and organizational psychology. Washington: American Psychological Association.

Statistical Office of the Slovak Republic. (2019). Gross earnings and median with another descriptive statistics. Retrieved from: http://statdat.statistics.sk/cognosext/cgibin/cognos.cgi?b_action=cognosViewer\&ui.action=run\&ui.object $=$ storeID $(\% 22 \mathrm{iFE} 32 \mathrm{FB}$ CAEB0F4E00A94321FB61D9FC04\%22)\&ui.name=Gross\%20earnings\%20and\%20desc riptive $\% 20$ statistics $\% 20 \% 5 \mathrm{bnp} 1103 \mathrm{rr} \% 5 \mathrm{~d} \&$ run.outputFormat $=\&$ run.prompt $=$ true $\& \mathrm{cv}$.he ader $=$ false \&ui.backURL=\% 2 fcognosext $\% 2$ fcps $4 \% 2$ fportlets $\% 2$ fcommon $\% 2$ fclose.html \&run.outputLocale $=\mathrm{en}$

Viechtbauer, W. (2010). Conducting Meta-Analyses in R with the metafor Package. Journal of Statistical Software, 36(3). doi:10.18637/jss.v036.i03

Wicherts, J. M., \& Scholten, A. Z. (2013). Comment on "Poverty Impedes Cognitive Function". Science, 342(6163), 1169-1169. doi:10.1126/science.1246680

Wicherts, J. M., Veldkamp, C. L. S., Augusteijn, H. E. M., Bakker, M., van Aert, R. C. M., \& van Assen, M. A. L. M. (2016). Degrees of Freedom in Planning, Running, Analyzing, and Reporting Psychological Studies: A Checklist to Avoid p-Hacking. Frontiers in Psychology, 7:1832. doi: 10.3389/fpsyg.2016.01832 